\title{
Use of Sequential, Single and Kinetic Extractive Schemes to Assess Cadmium (Cd) and Lead (Pb) Availability in Vietnamese Urban Soils
}

\author{
Nastaran Manouchehri1 ${ }^{1}$, Thi Minh Loi Nguyen², Stéphane Besancon1', Lan Anh Le ${ }^{3}$, \\ Alain Bermond ${ }^{2}$ \\ ${ }^{1}$ AgroParisTech, UMR 1145, Paris, France \\ ${ }^{2}$ AgroParisTech, Laboratoire de Chimie Analytique, Paris, France \\ ${ }^{3}$ Laboratory of Analytical Science and Technology, Institute of Chemistry, Hanoi, Vietnam \\ Email: manouche@agroparistech.fr, minhloinguyen@gmail.com, sbesancon@agroparistech.fr, \\ lananhle2003@yahoo.com, alain.bermond@agroparistech.fr
}

Received 2 October 2014; revised 18 November 2014; accepted 3 December 2014

Copyright (C) 2014 by authors and Scientific Research Publishing Inc.

This work is licensed under the Creative Commons Attribution International License (CC BY).

http://creativecommons.org/licenses/by/4.0/

(c) $\underset{\mathrm{EY}}{(1)}$ Open Access

\begin{abstract}
Modified BCR sequential extraction, single equilibrium-based EDTA extraction and kinetic fractionation were used for estimating the $\mathrm{Pb}$ and $\mathrm{Cd}$ availability in a series of soil samples from 3 sites located in urban areas of Hanoi (Vietnam). These schemes were compared to identify a simple, rapid and cheap protocol for routine estimation of $\mathrm{Pb}$ and $\mathrm{Cd}$ remobilizable fraction and the related potential risk. The comparison of these three approaches revealed their convergence in terms of mobility patterns observed for $\mathrm{Pb}$ and $\mathrm{Cd}$. $\mathrm{Cd}$ was characterized by higher extractibality and mobility whatever the approach. $\mathrm{Pb}$ was distinguished of $\mathrm{Cd}$ by its high association to Fe-oxides, lower extractability, lower rate of desorption and then lower mobility. For this environmental scenario, EDTA single scheme at equilibrium could be suggested as the best suited and a simple protocol for determination of the labile pool of $\mathrm{Cd}$ and $\mathrm{Pb}$. The pseudo-total concentrations of $\mathrm{Pb}$ and $\mathrm{Cd}$ are actually below the Vietnamese standard level, contrary to the results obtained by other authors for agricultural soils at other urban sites of Hanoi.
\end{abstract}

\section{Keywords}

Trace Metal, Soil, Sequential Extraction, Kinetic Fractionation 


\section{Introduction}

According to the report of Vietnam's Ministry of Natural Resources and Environment [1], soil environment is affected by Trace Metals “TMs” pollution, particularly the agricultural soil environments of suburbs and villages around metal recycling industries. Use of chemical fertilizers and pesticides in agriculture, industrial activities and toxic chemicals (remaining outstanding after the war), and finally use of wastewater from urban and industrial zones (after the rapid expansion of Hanoi City) are evoked as principal reasons of contamination [2].

It is widely accepted that total metal concentration is not a relevant indicator for assessing the risks posed by the presence of TMs for the environment and the food chain. TMs in soils may exist in different chemical and physical forms due to their binding to different soil constituents. The determination of these different forms; usually called "speciation" or "fractionation"1 gives more information on mobility, bioavailability and potential toxicity of TMs and, consequently, on the related risks [3]. The free metal ions and the labile complexes are usually considered as the fraction of TMs that causes the most significant biological effects.

To determine the different binding pools and to provide information on the potential mobility and bioavailability of TMs, chemical extractive approaches (single or sequential schemes) have been widely used in the literature, developed and modified over recent decades [5]-[13].

BCR (Community Bureau of Reference) protocol has been developed, modified and generalized as an attempt to harmonize different methodologies of the sequential extraction process applied in different studies to soil and sediments [7] [9] [12] [14] [15]. A three steps modified BCR scheme was proposed [16] based on acetic acid, hydroxyl ammonium and hydrogen peroxide extraction associated, respectively, with weakly bound, reducing and oxidizable fractions.

A large range of single extraction schemes have been also developed using one extractive agent such as EDTA to simulate TM exchange in soil/solution systems [17]-[21]. Because of its non-specific nature, EDTA extracts cations bound to several components of soil solid phase (exchangeable, surface adsorbing site, carbonate, organic mater and amorphous Fe and Mn oxides).

Extractive approaches are generally applied at pseudo-equilibrium conditions while soil system is a dynamic environmental medium. Hence, several scientists focused on kinetic approaches like as kinetic fractionation [22][27] and Diffusive Gradient in Thin film "DGT” technique [28] [29] for simulating the TMs dynamic exchange at the soil/soil solution interface.

Many works employed extractive schemes to assess trace elements availability and accessibility in soils for many years. These extractive schemes are generally used separately. This paper deals with the comparison of three already described approaches, considering both thermodynamic and kinetic aspects, in order to evaluate the availability/leachability of $\mathrm{Pb}$ and $\mathrm{Cd}$ in soils from three different sites located in the suburbs of Hanoi in Vietnam. The information issued from each approach will be used to evaluate its contribution or complementarities for assessing the remobilization of $\mathrm{Pb}$ and $\mathrm{Cd}$ in these samples and finally to identify a simple, rapid and cheap protocol for routine estimation of $\mathrm{Pb}$ and $\mathrm{Cd}$ remobilized fraction. For this purpose, three extractive schemes are proposed:

a) Modified BCR sequential extraction with three steps to identify the metal distribution between different soil constituents.

b) Single equilibrium-based extraction in soil-EDTA system. EDTA single scheme will be used as an indicator of a reliable pool of mobilizable metal.

c) Kinetic fractionation in soil-EDTA system as a simple and rapid procedure giving some complementary information on the metal lability.

\section{Materials and Methods}

\subsection{Soil Samples}

Seven soil samples were collected (at the surface horizon 0 - $20 \mathrm{~cm}$ ) from three vegetable growing areas in suburbs

\footnotetext{
${ }^{1}$ According to Templeton et al. [4], the speciation of an element is the distribution of an element amongst defined chemical species in a system. Fractionation is the process of classification of an analyte or a group of analytes from a certain sample according to physical (e.g. size, solubility) or chemical (e.g. bonding, reactivity) properties. In case that it is not possible to determine the concentration of the different individual chemical species that sum up the total concentration of an element in a given matrix, that means it is impossible to determine the speciation, it is a useful practice to do fractionation instead. The term speciation is then not recommended in this work when using single or sequential extraction.
} 
of old Hanoi, Viet Nam and associated with two rivers (cf. Figure 1. for the map of sampling sites on Hanoi area): the Nhue (Cau Dien site) and the To Lich (Thanh Liet site). The domestic and industrial wastewaters of the city are directly discharged into the To Lich River without any prior treatment. The water of these rivers supplies the vegetable growing areas of the river borders. Cau Dien region is polluted by domestic waste water directly. The Thanh Liet cultivating region was irrigated by wastewater from the Thanh Liet Paint factory. The Dong Anh site is located in an industrial zone of old Hanoi, but there is also a vegetable cultivating area alongside the stream contaminated by waste water from the Dong Anh roofing plant and Dong Anh Mechanical Company.

Some physico-chemical characteristics of the soils are described in Table 1.

\subsection{Apparatus and Chemical Reagents}

A Polarized Zeeman Atomic Absorption spectrophotometer model Z 5000 (Hitachi) was used for the metal determinations by ETAAS (Electrothermal Atomic Absorption Spectrometry) with platform cuvette for Cd and $\mathrm{Pb}$ and FAAS (Flame Atomic Absorption Spectrometry) for Ca and Fe.

All reagents used to prepare the extracting solutions were products of analytical-grade quality. Water of high purity obtained from a Millipore apparatus (water resistivity $=18 \mathrm{M} \Omega \cdot \mathrm{cm}$ ) was used for solution preparation. The polyethylene flasks were cleaned in $1 \mathrm{~mol} \cdot l^{-1}$ nitric acid and then rinsed with pure water. A Digestion block was used for digestion of the soil samples and for sequential extraction protocol.

\subsection{Experimental Procedures}

\subsubsection{Pseudo-Total Determination}

The total metal content $(\mathrm{Pb}, \mathrm{Cd}, \mathrm{Ca}, \mathrm{Fe})$ was determined by digestion with aqua regia $\left(1 / 4 \mathrm{HNO}_{3}, 3 / 4 \mathrm{HCl}\right)$. All the digestions were conducted in triplicate and the ratio of $\mathrm{m}_{\text {soil }} / \mathrm{v}$ was $1 / 10$. A Digestion block (DigiPREP; SCP

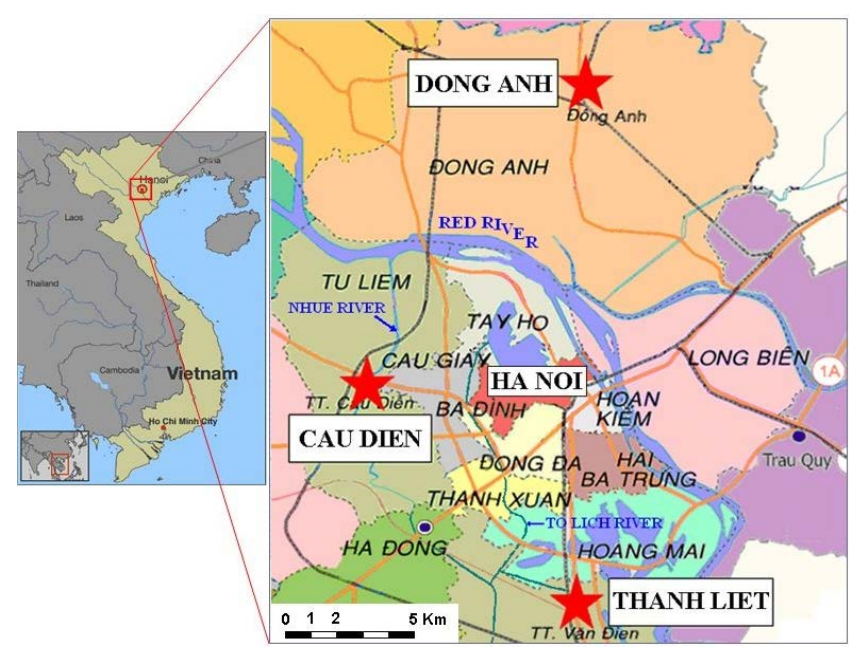

Figure 1. Map of sampling sites on Hanoi area.

Table 1. Some physico-chemical soil characteristics.

\begin{tabular}{|c|c|c|c|c|c|c|c|}
\hline Sample (site) & $\mathrm{C}_{\text {org }} \mathrm{g} / \mathrm{kg}$ & MO g/kg & $\mathbf{p H}$ & $\mathrm{CaCO}_{3 \text { tot }} \mathrm{g} / \mathrm{kg}$ & $\begin{array}{c}\mathrm{P}_{2} \mathrm{O}_{5} \mathbf{g} / \mathbf{k g} \\
\text { Joret- Herbert }\end{array}$ & $\mathbf{M n}_{\text {total }}$ HF mg/kg & $\mathrm{Fe}_{\text {total }} \mathrm{HF} \mathbf{g} / \mathbf{k g}$ \\
\hline 2T4 (Cau Dien) & 64.9 & 112 & 7.57 & 5.1 & 0.68 & 509 & 49.9 \\
\hline 4T3 (Dong Anh) & 11.7 & 20.3 & 8.75 & 5.4 & nd & 395 & 44.1 \\
\hline $6 T 1$ (Thanh Liet) & 17.0 & 29.4 & 5.94 & $<1$ & nd & 543 & 60.6 \\
\hline 8T4 (Dong Anh) & 11.1 & 19.2 & 5.52 & $<1$ & 0.16 & 79.5 & 9.1 \\
\hline 2T1 (Cau Dien) & 38.0 & 65.8 & 8.00 & $<1$ & nd & 535 & 48.8 \\
\hline 4T4 (Dong Anh) & 19.8 & 34.3 & 7.02 & $<1$ & 0.05 & 434 & 33.8 \\
\hline 6T2 (Thanh Liet) & 12.7 & 22.0 & 8.28 & 7.7 & 0.15 & 423 & 34.5 \\
\hline
\end{tabular}


Science) was used for digestion of the soil samples. RSD values for three replicates did not exceed 3\%.

\subsubsection{Sequential Extraction Protocol}

A modified BCR extraction scheme, where the final part was digestion with aqua regia, was applied in order to determine $\mathrm{Cd}$ and $\mathrm{Pb}$ contents in each fraction of the soil solid phase [12]. A brief description of this procedure is provided below.

\section{$\underline{\text { Step } 1}$}

$40 \mathrm{ml}$ of acetic acid $\left(0.11 \mathrm{~mol} \cdot \mathrm{l}^{-1}\right)$ were added to $1 \mathrm{~g}$ of soil (shaking for $\left.16 \mathrm{~h}\right)$. The extract was separated from the solid residue by centrifugation, filtered with a Millipore syringe filter membrane $(0.45 \mu \mathrm{m})$ and stored in a polyethylene container at $4^{\circ} \mathrm{C}$ for analysis. The residue was washed with $20 \mathrm{ml}$ of Milli-Q water (shaking for 20 min), centrifuged and the washings discarded.

$\underline{\text { Step } 2}$

$40 \mathrm{ml}$ of hydroxyl ammonium chloride solution $\left(0.5 \mathrm{~mol} \cdot \mathrm{l}^{-1}, \mathrm{pH}=2\right)$ were added to the residue of step 1 . The extraction procedure was then performed as in step 1.

\section{Step 3}

$10 \mathrm{ml}$ of Hydrogen peroxide solution (30\%) were added to the residue from step 2 and digested at room temperature for $1 \mathrm{~h}$. The digestion was continued by heating at $85^{\circ} \mathrm{C}$ in the digestion block for $1 \mathrm{~h}$ to reduce the volume to less than $3 \mathrm{ml}$. A second aliquot of hydrogen peroxide solution $(30 \%, 10 \mathrm{ml})$ was added and the digestion procedure was repeated. $50 \mathrm{ml}$ of ammonium acetate $\left(1 \mathrm{~mol} \cdot \mathrm{l}^{-1}, \mathrm{pH}=2\right)$ was added to the cool moist residue. The sample was shaken, centrifuged and the extract was separated as described in step 1.

$\underline{\text { Residual }}$

$12 \mathrm{ml}$ of aqua regia were added to the solid residue from step 3 and the sample was digested before analysis.

\subsubsection{Single Extraction Protocol}

$10 \mathrm{ml}$ of EDTA solution ( $0.002 \mathrm{~mol} \cdot \mathrm{l}^{-1}$, prepared from EDTA disodium salt, $\mathrm{pH}$ adjusted to 6.5$)$ were added to $1 \mathrm{~g}$ of soil sample, and then shaken for 24 hours. The samples were centrifuged and then filtered $(0.45 \mu \mathrm{m})$ for $\mathrm{Pb}$, $\mathrm{Cd}$, Ca, Fe measurement.

\subsubsection{Kinetic Protocol}

The kinetics of metal extraction by EDTA (0.002 mol. $\mathrm{l}^{-1}$ EDTA, $\mathrm{pH}$ adjusted to 6.5), were conducted for a soil/solution ratio of $1: 10$ [26] [30]. The mixture was stirred on a rotary stirrer over a period of 24 hours. At selected time intervals $(4,8,12,15,20,30,45,60,90,120,150,200,250,300$ and 1440 minutes), an aliquot of 0.5 $\mathrm{ml}$ of the mixture was removed via syringe and immediately filtered $(0.45 \mu \mathrm{m})$. The filtrates were analysed.

\subsection{Statistical Analysis}

The software Sigmaplot 5.0 was used for fitting the kinetic experimental data to the appropriate equation. It was also used for data smoothing. In all cases, regression and statistical tests were used to determine the goodness of the fit once all of the required parameters were determined. XLSTAT was also used for principal component analysis (PCA).

\section{Results and Discussion}

\subsection{Total Concentrations}

The average values of pseudo-total concentrations of $\mathrm{Pb}$ and $\mathrm{Cd}$ (Table 2) were in the following order: $\mathrm{Pb}$ (38 $\left.\mathrm{mg} \cdot \mathrm{kg}^{-1}\right)>\mathrm{Cd}\left(0.51 \mathrm{mg} \cdot \mathrm{kg}^{-1}\right)$, with some variability observed for the samples collected from the same site due to the distance of the sampling points from the rivers. Some notorious differences in physico-chemical properties were also observed between samples from the same site (Table 1). For example, the two samples from Thanh Liet have different contents of $\mathrm{CaCO}_{3}$, different pH's (5.94 and 8.28), different Fe contents (60.6 and $34.5 \mathrm{~g} / \mathrm{kg}$ ) and finally different total contents of $\mathrm{Pb}\left(51.2\right.$ and $35.1 \mathrm{mg} \cdot \mathrm{kg}^{-1}$ ) and $\mathrm{Cd}\left(1.3\right.$ and $\left.0.46 \mathrm{mg} \cdot \mathrm{kg}^{-1}\right)$. These notorious differences between samples from the same site could be related to the different sampling point. Huong et al. [31] evaluated the heavy-metal contamination of soil at another site of the suburbs of Hanoi located at Tam Hiep Commune of Than Tri District, which is also irrigated by water from the To Lich River (not far from the Than Liet 
Table 2. Pseudo-total concentrations of $\mathrm{Cd}$ and $\mathrm{Pb}$ (aqua regia digestion) in Vietnamese soils vs. those in some Fenche agricultural soils. For all measurements, the average of SD for 3 replicates did not exceed $4 \%$.

\begin{tabular}{|c|c|c|c|}
\hline & Sample & $\mathrm{C}_{\mathrm{Pb}}\left(\mathrm{mg} \cdot \mathrm{kg}^{-1}\right)$ & $\mathrm{C}_{\mathrm{Cd}}\left(\mathrm{mg} \cdot \mathrm{kg}^{-1}\right)$ \\
\hline \multirow{7}{*}{ Vietnamese soils } & 2T4 (Cau Dien) & 47.72 & 0.78 \\
\hline & 4T3 (Dong Anh) & 33.13 & 0.14 \\
\hline & $6 \mathrm{~T} 1$ (Thanh Liet) & 51.24 & 1.30 \\
\hline & 8T4 (Dong Anh) & 16.70 & 0.08 \\
\hline & 2T1 (Cau Dien) & 44.23 & 0.52 \\
\hline & 4T4 (Dong Anh) & 38.17 & 0.31 \\
\hline & $6 \mathrm{~T} 2$ (Thanh Liet) & 35.19 & 0.46 \\
\hline \multirow{5}{*}{ French soils } & Grimault & 40.91 & 0.86 \\
\hline & Bierry & 45.22 & 0.27 \\
\hline & Courtenay & 37.71 & 0.51 \\
\hline & Chaponne & 82,02 & 0.56 \\
\hline & Vellerot & 44.81 & 0.46 \\
\hline
\end{tabular}

site). The authors attributed the heavy metal contamination to the use of polluted irrigation water and observed a marked decrease of the concentration of heavy metals with distance of the sampling point from the canal.

The total contents were compared to those obtained by other authors for agricultural soils at other sites in the suburbs of Hanoi, irrigated by the same rivers. According to Huong et al. (2010), the concentrations of metals were much greater than the background level in that area and exceeded the permissible levels of the Vietnamese standards for $\mathrm{Cd}$ and $\mathrm{Pb}$ in agricultural grounds. In another study [32], the authors show that the sediments in the Nhue River are heavily polluted by cadmium and lead $\left(0.7-8.7 \mathrm{mg} \cdot \mathrm{kg}^{-1}\right.$ for $\mathrm{Cd}$ and $77-433 \mathrm{mg} \cdot \mathrm{kg}^{-1}$ for Pb). In our work, $\mathrm{Pb}$ and $\mathrm{Cd}$ levels even in the most polluted sample (6T1 collected from Thanh Liet site) was below the Vietnamese standard level [33] and the three sites could be actually considered as non-polluted. However, the situation may change in future due the transfer and accumulation of TM's in the cultivating soil, uptake by vegetable, and then the potential toxicity risk for human.

The pseudo-total concentrations were finally compared to the typical ranges in some French (Burgundy region) agricultural unpolluted soils [34]. These soil samples belong to a series of samples for which the origin of natural contents of trace metals results from geological evolution and were collected at sites across the southern part of the Yonne district, Burgundy, France. Average total contents of $\mathrm{Cd}$ and $\mathrm{Pb}$ in Vietnamese soils are similar to unpolluted French (Burgundy) agricultural soils (Table 2).

\subsection{Chemical Fractionation at Equilibrium}

\subsubsection{Sequential Extraction}

A modified BCR extraction scheme [16] was employed to determine the $\mathrm{Pb}$ and $\mathrm{Cd}$ content bound to different soil components dividing them into exchangeable fraction (acid-soluble, carbonate and exchangeable bound, step 1), reducing fraction (metal bound to Fe- or Mn-oxides, step 2) and oxidizable fraction (organic and sulphide bound, step 3). The residual fraction involves the strongest binding with crystalline structure [9]. The results are reported as the mean value for two replicates in 7 samples (Figure 2). The RSD values in each step did not exceed $6 \%$. The use of certified reference materials was unfortunately not possible to validate the quality of the obtained results. A comparison of the sum of $\mathrm{Cd}$ and $\mathrm{Pb}$ concentrations obtained from BCR relative to the total digestion values (pseudo-total concentrations) showed recoveries close to 100\% (ranging from 97\% to 106\% for Cd and from 79\% to $113 \%$ for $\mathrm{Pb}$ ). In some cases, the source of recovery errors could be associated to the analytical measurements (trace values close to the limit of detection).

Cd: For Cd, the highest amount of pseudo-total content was contained in the exchangeable fraction (step 1) ranging from $34 \%$ to $79 \%$ and in the reducing fraction i.e. iron and manganese oxides (step 2) ranging from $18 \%$ to $49 \%$ of total content. Step 3 (oxidizable-organic matter "OM" and sulphides) released only within the range of $2 \%$ to $10 \%$ of the total content. For $8 \mathrm{~T} 4$ (sandy and acid soil), up to $80 \%$ of Cd was found in the exchangeable fractions. This behaviour could be related to the very low content of $\mathrm{F}_{2}$ potential binding sites (Fe-/Mn-oxides) in 
$\mathrm{Pb}$

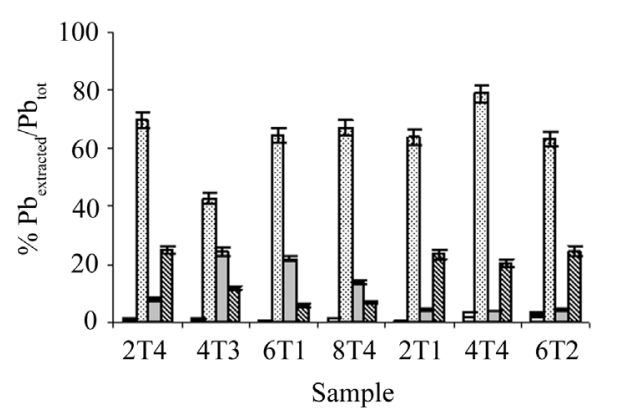

$\mathrm{Cd}$

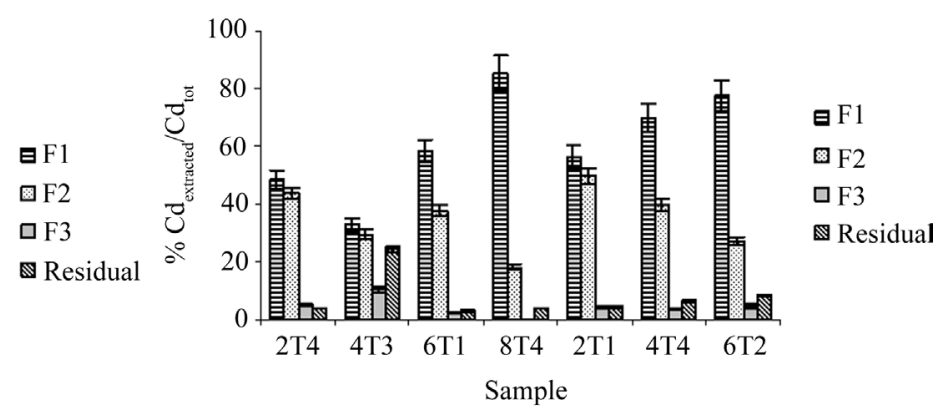

Figure 2. BCR fractionation of $\mathrm{Pb}$ and $\mathrm{Cd}$ in seven soil samples. Error bars are \pm 1 S.D. of duplicate measurements.

this sample. These findings suggest that Cd probably interacts strongly with carbonates and Fe-/Mn oxides in the studied samples.

The results showed that a very low part of Cd is immobilized and more than $90 \%$ of the Cd is associated to the first three fractions (step $1+$ step $2+$ step 3 ) dealing with its relative high mobility in the studied soils. This behaviour has been already reported in the literature for Cd [5] [35]-[37].

Pb: Unlike Cd, very small amounts of $\mathrm{Pb}$ were released during step 1 (exchangeable fraction) ranging from $0.6 \%$ to $3.2 \%$. The highest concentration of $\mathrm{Pb}$ in all samples ( $42 \%$ to $79 \%$ of total $\mathrm{Pb}$ ) was contained in the reducing fraction (step 2), showing that it occurs in the forms bound to Fe/Mn oxides. This trend is already reported by some authors [5] [38]-[40]. Residual fraction presents smaller amounts of total Pb for all samples (from $6.3 \%$ to 25.9\%), but higher than those observed for Cd.

According to BCR, a major part of total Cd was associated to the exchangeable fraction while Pb was found mostly in reducing fraction whatever the origin of the sample (3 different sites). $\mathrm{Pb}$ and $\mathrm{Cd}$ immobilized forms (residual) were not abundant in the studied soils. The order of mobility, which is in agreement with the trends frequently reported in the literature [5] [41]-[46] was as follows: Cd > Pb, Cd being preferentially associated with more remobilized fractions.

\subsubsection{Single Extraction Scheme}

The experimental protocol of $24 \mathrm{~h}$ extraction (pseudo-equilibrium) was carried out using single extraction scheme by $2 \times 10^{-3} \mathrm{~mol} \cdot \mathrm{l}^{-1}$ EDTA [30]. Table 3 summarizes the mean values $\mathrm{Pb}$ - and $\mathrm{Cd}$-EDTA extracted contents in two replicates for 7 investigated soils. Difference between two measurements did not differ by more than 5\%. EDTAextracted fractions $\left(\mathrm{F}_{\mathrm{EDTA}}\right)$ ranged from $30.1 \%$ to $94.8 \mathrm{c}$ of total content for $\mathrm{Cd}$ and from $9.1 \%$ to $57.6 \%$ of total content for $\mathrm{Pb}$. Average contents of Cd-EDTA fraction were higher than Pb-EDTA for all investigated samples indicating relative higher availability for Cd using EDTA $0.002 \mathrm{~mol} \cdot \mathrm{l}^{-1}$.

The metal mobile pool measured by EDTA is generally an "operationally" defined fraction because the nonselective extractability of EDTA depends strongly on experimental conditions and soil matrix (soil physicochemical properties, source of metal contamination and metal distribution within different mineral phases). EDTA extraction yield was affected by $\mathrm{pH}$ i.e. the metal-EDTA extracted decreases with $\mathrm{pH}$ increase (Figure 3).

The $\mathrm{pH}$ is reported by several authors as a crucial factor affecting the metal solubility [22] [23] [47] [48]. However, Fangueiro et al. [24] reported no $\mathrm{pH}$ changes during the kinetic extraction of $\mathrm{Cd}$ and $\mathrm{Pb}$ from sediments at high concentrations of EDTA $\left(0.05 \mathrm{~mol} \cdot \mathrm{l}^{-1}\right)$ because of its buffering capacity. The extraction efficiency becomes dependent on $\mathrm{pH}$ and major cation contents (especially $\mathrm{Ca}$ and $\mathrm{Fe}$ ) at low concentrations of EDTA [23] [47].

Otherwise, some authors report that in alkaline conditions the metal is more strongly fixed to the solid phase reducing its solubility e.g. Cd binding to calcites in calcareous soils [49]-[51]. In the operational conditions used in the present work (low concentration of EDTA employed for soils with different $\mathrm{pH}$ ), $\mathrm{Cd}$ and $\mathrm{Pb}$ extractability changed with $\mathrm{pH}$. Higher mobility is observed for acidic $\mathrm{pH}$ (release of $94.8 \%$ of total $\mathrm{Cd}$ at $\mathrm{pH}=5.6$ against $30.1 \%$ at $\mathrm{pH}=8.15)$.

\subsection{Kinetic Fractionation}

The kinetics of Cd- and Pb-EDTA extraction was investigated for only 6 samples in two replicates. In order to 
Table 3. Pb- and Cd-EDTA fractions released after $24 \mathrm{~h}$ of reaction in 7 studied soils.

\begin{tabular}{ccc}
\hline Sample & $\mathbf{\%} \mathbf{C} \mathbf{d}_{\text {EDTA }} / \mathbf{C d}_{\text {tot }}$ & $\mathbf{\%} \mathbf{P b}_{\text {EDTA }} / \mathbf{P b}_{\text {tot }}$ \\
\hline 2T4 & 55.56 & 28.95 \\
4T3 & 30.15 & 9.17 \\
$\mathbf{6 T 1}$ & 80.7 & 25.01 \\
$\mathbf{8 T 4}$ & 94.81 & 57.62 \\
2T1 & 63.55 & 16.62 \\
$\mathbf{4 T 4}$ & 82.05 & 55.24 \\
$\mathbf{6 T 2}$ & 46.15 & 12.95 \\
\hline
\end{tabular}

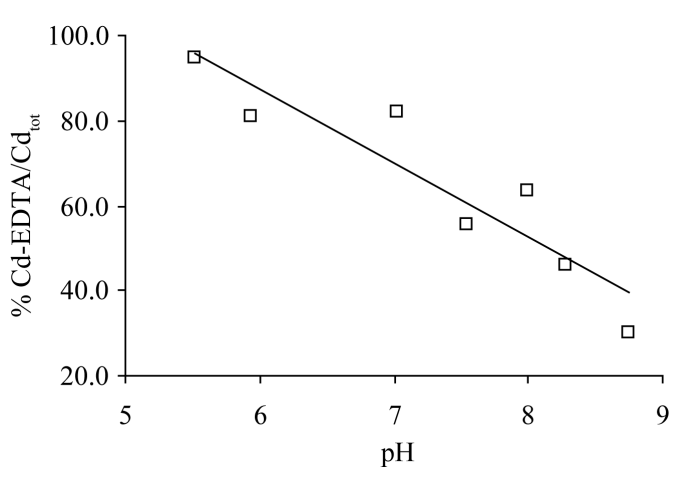

(a)

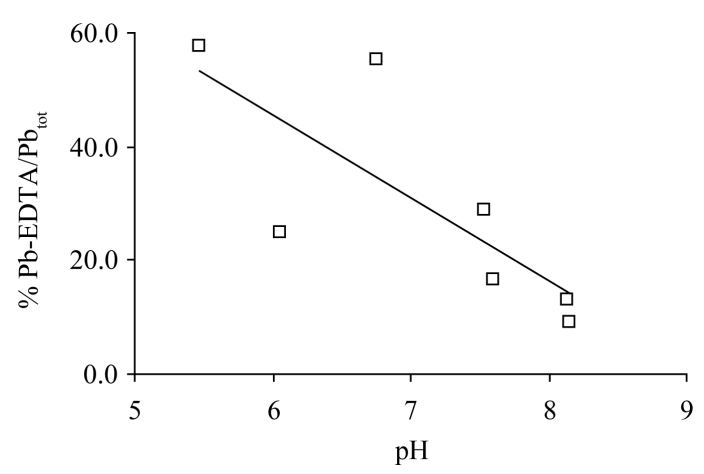

(b)

Figure 3. Effect of $\mathrm{pH}$ on $\mathrm{Cd}(\mathrm{a})$ and $\mathrm{Pb}$ (b) extraction in soil-EDTA system. $\mathrm{pH}$ values represent the final $\mathrm{pH}$ of soil solution.

simulate the kinetics of metal desorption, the kinetic data (metal extracted with time) were preliminary exploited using the classical rate equation, as proposed by Labanowski et al. [45]:

$$
\frac{\Delta \mathrm{M}}{\Delta \mathrm{t}}=\frac{\mathrm{M}_{2}-\mathrm{M}_{1}}{\mathrm{t}_{2}-\mathrm{t}_{1}}
$$

where $\Delta \mathrm{M} / \Delta \mathrm{t}$ is the average desorption rate per time unit and is computed from the ratio of desorbed mass evolution $\left(\mathrm{M}_{2}-\mathrm{M}_{1}\right)$ to desorption time evolution $\left(\mathrm{t}_{2}-\mathrm{t}_{1}\right)$ for two consecutive samplings. Figure 4 displays, as example, the evolution of desorption rate with time for $\mathrm{Pb}$ and $\mathrm{Cd}$ in sample 6T2. The same kinetic trend was observed for other samples.

An overall two-segments shape was observed in the evolution of desorption rate of both cations in all samples indicating two kinetically distinguishable pools which correspond to two metal fractions characterized by two different desorption rates i.e. high desorption rate in the beginning of the leaching followed by a decrease in higher reaction time.

Considering this overall trend, a two reaction model, based on a pseudo-first order kinetic equation rate, was used to represent the sum of two distinct patterns characterized by a fast leaching phase and a second slower pattern. The model should provide the concentration of metal in the two pools, $Q_{L}\left(\mu \mathrm{g} \cdot \mathrm{g}^{-1}\right)$ or the concentration of the "labile" (quickly extracted) pool, $\mathrm{Q}_{\mathrm{SL}}\left(\mu \mathrm{g} \cdot \mathrm{g}^{-1}\right.$ ) or the concentration of the "less labile" (less quickly extracted) pool. This model has been used by several authors for estimating the metal mobility in different environmental matrices [9] [23] [25] [26] [45] [52]-[54]. The estimated labile pool is representative of the potential availability of the target cation [55]. $\mathrm{k}_{\mathrm{l}}\left(\mathrm{min}^{-1}\right)$ and $\mathrm{k}_{\mathrm{sl}}\left(\mathrm{min}^{-1}\right)$ are the rate constants of desorption associated with these pools.

$$
\mathrm{Q}(\mathrm{t})=\mathrm{Q}_{\mathrm{L}}\left(1-\mathrm{e}^{-\mathrm{k}_{\mathrm{L}}^{\mathrm{t}}}\right)+\mathrm{Q}_{\mathrm{SL}}\left(1-\mathrm{e}^{-\mathrm{k}_{\mathrm{SL}} \mathrm{t}}\right)
$$

The theoretical principles of this kinetic model are described in detail in a previous paper [26]. The model assumes that the leaching process can be considered as pseudo 1st-order reaction (excess of the reagent or constant concentration of the reagent vs. time. The condition required to employ this model (constant concentration of EDTA vs. time even if the system is in lack of EDTA with respect to all extractable cations) was then well verified. 
$\mathrm{Cd}$
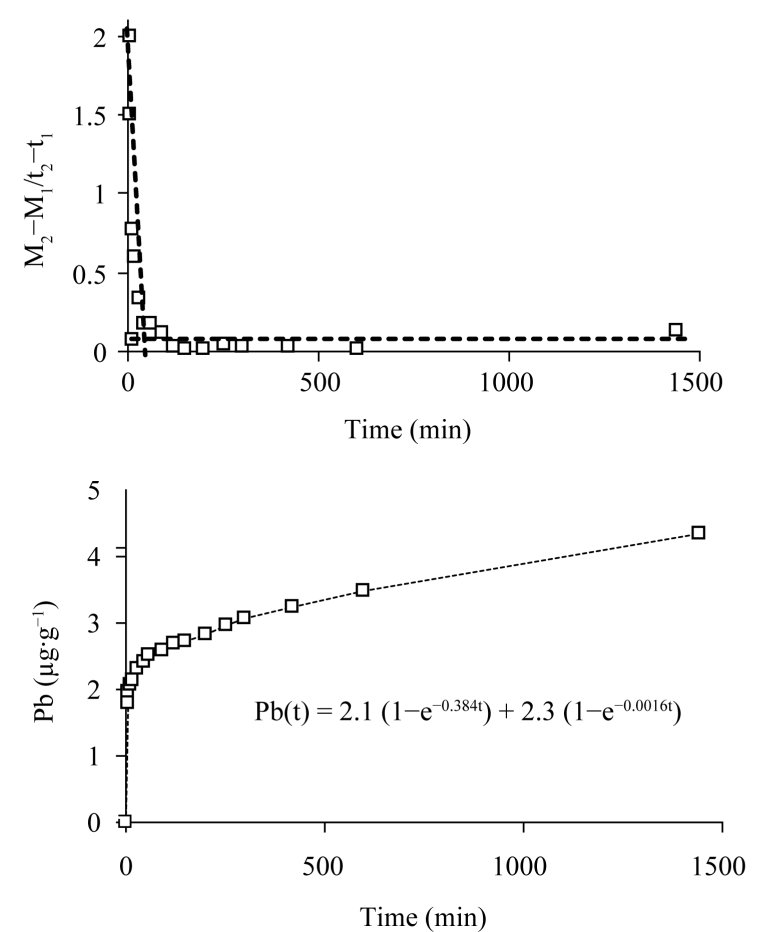

$\mathrm{Pb}$
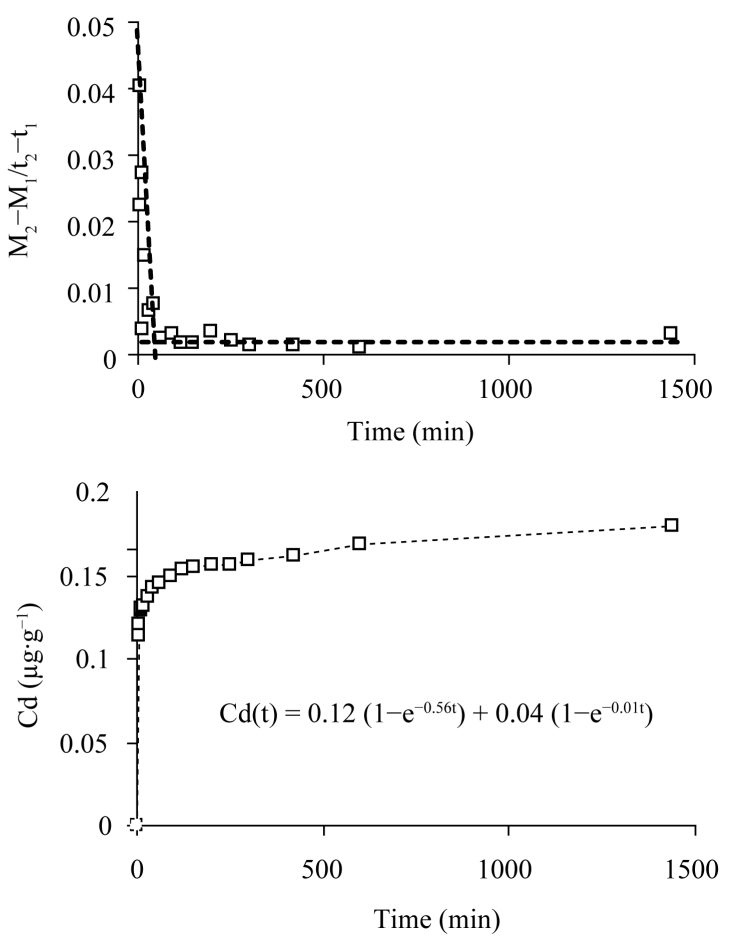

Figure 4. Evolution of desorption rate and fitting of kinetic experimental data to the two-reaction model for $\mathrm{Pb}$ and $\mathrm{Cd}$ in 6T2 sample-EDTA system.

The labile and less labile pools present the operationally-defined metal concentration desorbed from different chemical soil constituents. Contrary to BCR protocol, this method does not involve a real soil fraction such as iron oxides or carbonates but it can be applied to predict an overall labile fraction.

Figure 4 shows an example of the fitting of kinetic experimental data to the pseudo 1st order model for (Equation (2)). Leaching experimental data were well fitted to Equation (2) with R values generally over 0.96 $(0.0001<\mathrm{p}<0.0005)$.

The labile $\left(\mathrm{F}_{\mathrm{L}}\right)$ and less labile $\left(\mathrm{F}_{\mathrm{SL}}\right)$ fractions of $\mathrm{Cd}$ and $\mathrm{Pb}$ and the associated kinetic constants were estimated from the kinetic simulation for all samples (Table 4). Labile and less labile pools are expressed as fractions of total contents in soil in order to compare with metal fractions obtained by BCR and single schemes.

For all studied samples, $20 \%$ to $53 \%$ of total Pb-EDTA fraction corresponds to the labile pool while Cd-EDTA fraction involves more than $55 \%$ of labile form. The constant rate of the desorption of Cd labile fraction $\left(\mathrm{k}_{\mathrm{L}}\right.$ ranging from 0.40 to $0.73 \mathrm{~min}^{-1}$ ) revealed higher than that for $\mathrm{Pb}\left(\mathrm{k}_{\mathrm{L}}\right.$ ranging from 0.21 to $0.40 \mathrm{~min}^{-1}$ ) for all samples. Kinetic simulations estimate therefore a higher mobility and hence potential availability for $\mathrm{Cd}$.

\subsection{Comparison of Labile Pools Estimated by Sequential, Single and Kinetic Schemes}

The metal fractions estimated by different procedures (BCR protocol, EDTA scheme and kinetic fractionation) were compared. Statistical correlations were performed considering different possible combinations between metal fractions issued from different methods. Only significant correlations will be discussed here.

Cd: Significant correlation $(r=0.91 ; p<0.005)$ was found between $F_{E D T A}$ and $F_{1}$ at equilibrium. BCR gived likely similar estimation of Cd contents in available pool for all samples (Figure 5). As shown previously, Cd was mainly contained in the exchangeable and reducing fractions, for the samples of all sites, which is in agreement with its higher extractability by EDTA and also with trends observed in the literature. Huong et al. [31] applied a sequential extraction scheme and a single extraction with EDTA to fractionate $\mathrm{Cd}$ and $\mathrm{Pb}$ in agricultural soils from the suburbs of Hanoi and observed that most of the Cd was contained in the reducible fraction and the results obtained by EDTA extraction followed the same trend observed in the present manuscript.

The kinetically labile pool $\left(\mathrm{F}_{\mathrm{L}}\right)$ did not correlate with $\mathrm{F}_{1}$ and any combination of BCR steps. Exchangeable 
Table 4. Labile fraction $\left(\mathrm{F}_{\mathrm{L}}=\% \mathrm{Q}_{\mathrm{L}} / \mathrm{Q}_{\mathrm{tot}}\right)$, less labile fraction $\left(\mathrm{F}_{\mathrm{L}}=\% \mathrm{Q}_{\mathrm{SL}} / \mathrm{Q}_{\mathrm{tot}}\right)$, associated constant rates $\left(\mathrm{k}_{\mathrm{L}}\right.$ and $\left.\mathrm{k}_{\mathrm{SL}}\right)$ and the percentage of labile fraction (\% QL/F $\mathrm{FDTA}_{\mathrm{EDA}}$ ) for $\mathrm{Pb}$ and $\mathrm{Cd}$ in 6 soil samples (RSD values did not exceed $5 \%$ ).

\begin{tabular}{|c|c|c|c|c|c|c|c|c|c|c|}
\hline \multirow{2}{*}{ Sample } & \multicolumn{5}{|c|}{$\mathbf{P b}$} & \multicolumn{5}{|c|}{ Cd } \\
\hline & $k_{L}\left(\min ^{-1}\right)$ & $\% \mathrm{~F}_{\mathrm{L}}$ & $\mathbf{k}_{\mathrm{SL}}\left(\min ^{-1}\right)$ & $\% \mathrm{~F}_{\mathrm{SL}}$ & $\% \mathrm{Q}_{\mathrm{L}} / \mathrm{EDTA}$ & $k_{L}\left(\min ^{-1}\right)$ & $\% \mathrm{~F}_{\mathrm{L}}$ & $\mathbf{k}_{\mathrm{SL}}\left(\min ^{-1}\right)$ & $\% \mathrm{~F}_{\mathrm{SL}}$ & $\% Q_{L} /$ EDTA \\
\hline $2 \mathrm{~T} 4$ & 0.21 & 7.94 & 0.002 & 21.01 & 27.47 & 0.40 & 42.91 & 0.005 & 12.64 & 77.45 \\
\hline $6 \mathrm{~T} 1$ & 0.26 & 10.40 & 0.007 & 14.61 & 41.59 & 0.59 & 74.92 & 0.006 & 5.77 & 92.88 \\
\hline $8 \mathrm{~T} 4$ & 0.33 & 27.72 & 0.007 & 29.90 & 48.12 & 0.73 & 70.13 & 0.013 & 24.68 & 74.07 \\
\hline $6 \mathrm{~T} 2$ & 0.38 & 3.37 & 0.002 & 13.25 & 47.65 & 0.57 & 35.50 & 0.011 & 28.05 & 59.15 \\
\hline $4 \mathrm{~T} 4$ & 0.34 & 28.76 & 0.009 & 26.47 & 52.10 & 0.67 & 56.41 & 0.005 & 25.64 & 68.93 \\
\hline $2 \mathrm{~T} 1$ & 0.40 & 6.17 & 0.001 & 6.78 & 20.34 & 0.78 & 27.25 & 0.008 & 18.90 & 55.98 \\
\hline
\end{tabular}

$\mathrm{Cd}$
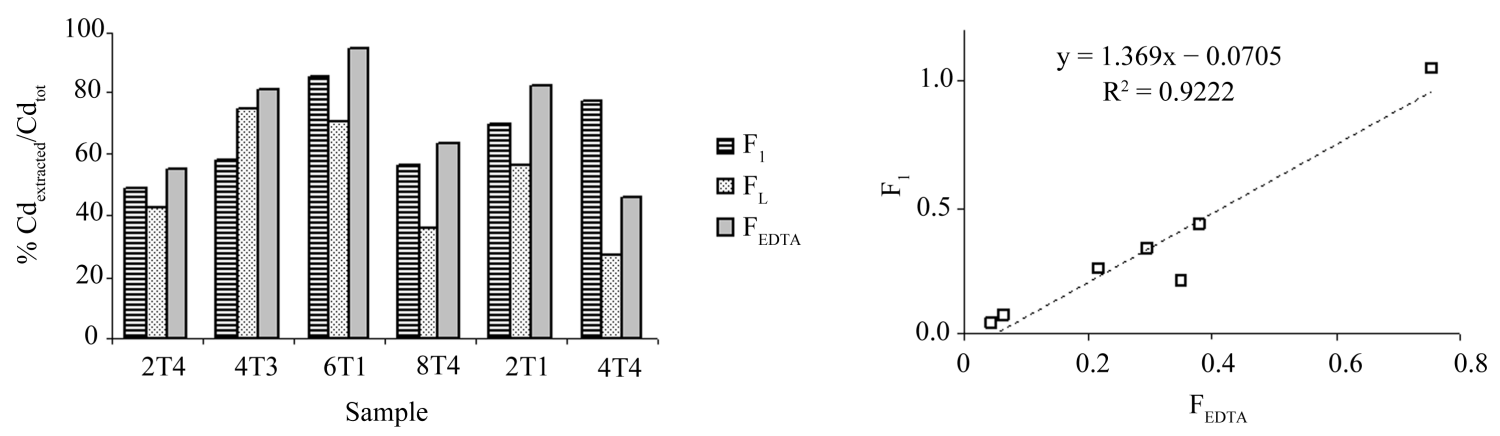

Figure 5. BCR fractionation vs. single and kinetic schems for $\mathrm{Pb}$ and $\mathrm{Cd}$ in 6 samples.

fraction $\left(\mathrm{F}_{1}\right)$ was correlated with the overall Cd-EDTA fraction $\left(\mathrm{F}_{\mathrm{EDTA}}\right.$ involving $\left.\mathrm{F}_{\mathrm{L}}+\mathrm{F}_{\mathrm{SL}}\right)$. This statistical analysis suggests that a fraction of $\mathrm{F}_{1}$ (Cd associated with carbonates in the soils) probably acted as less labile during the kinetic extraction under the operational conditions applied in this work (EDTA concentration).

Whatever the method used (BCR or single extraction), the exchangeable fraction of $\mathrm{Cd}$ decreased with $\mathrm{pH}$ increase indicating lower exchangeability in alkaline soils. Huang et al. [6] reported that in alkaline soils, Cd is mostly released from carbonate- and Fe-/Mn-oxide bound fractions.

$\underline{\mathbf{P b}}$ : Contrary to $\mathrm{Cd}$, Pb-EDTA fraction $\left(\mathrm{F}_{\mathrm{EDTA}}\right.$ ) did not represent a special fraction of BCR (Figure 5), even if it was significantly correlated $(r=0.61 ; p<0.005)$ with $F_{2}$ or $F_{1}+F_{2}$ (Pb contents in $F_{1}$ being negligible in all samples). It presented generally higher contents compared with $\mathrm{Pb}$ extracted in step $1\left(\mathrm{~F}_{1}\right) . \mathrm{F}_{\mathrm{EDTA}}$ was larger than $F_{1}$ because of the non selective nature of EDTA which extracts from all soil components (particularly from exchangeable, surface adsorbing sites, carbonates and amorphous Fe and Mn oxides) and not only from the exchangeable pool. However, the sum of the two steps releasing the exchangeable and reducing bound contents $\left(\mathrm{F}_{1}+\right.$ $\mathrm{F}_{2}$ ) was generally higher than $\mathrm{F}_{\mathrm{EDTA}}$ (Figure 6). EDTA extracted mostly from the reducing fraction i.e. the fraction bound to Fe- and Mn-oxides. Strong correlation (Figure 6) have been found between $\mathrm{Pb}$ and Fe contents extracted by EDTA showing that major part of $\mathrm{Pb}$ is associated to Fe-oxide and releases thus within the reducing step.

$\mathrm{F}_{2}$ was generally larger than $\mathrm{F}_{\mathrm{EDTA}}$ and then $\mathrm{F}_{\mathrm{L}}$. To compare the Pb extraction within $\mathrm{BCR}$ and EDTA schemes, Fe extraction has been considered because of $\mathrm{Pb}$ association with Fe-oxides. The low extraction of $\mathrm{Pb}$ by EDTA could be due to the lack of EDTA $\left(0.002 \mathrm{~mol} \cdot \mathrm{l}^{-1}\right.$ in this work) with respect to total metal extraction (major cations included like as $\mathrm{Ca}$ and $\mathrm{Fe}$ ). To verify this hypothesis, a mass balance was made between molar concentrations of EDTA initially introduced and metal extracted ( $\mathrm{Ca}, \mathrm{Fe}, \mathrm{Pb}$ and $\mathrm{Cd}$ ) according to the following equation:

$$
[\text { EDTA }]_{\text {total }}=[\text { EDTA }]_{\text {free }}+\sum[\mathrm{M}]_{\mathrm{TM}, \mathrm{Ca}, \mathrm{Fe}, \cdots}
$$

The mass balance showed that the system is in lack of EDTA with respect to all extractable cations for all samples. The major part of EDTA is complexed by $\mathrm{Ca}$ (readily released) and $\mathrm{Fe}$ (for non-calcareous acidic soils where $\mathrm{Ca}$ is not abundant). Figure 6 displays the relationship between $\mathrm{Ca}$ and $\mathrm{Fe}$ extraction. Fe is less extracted in calcareous soils (with alkaline $\mathrm{pH}$ ) and the mass balance is dominated by $\mathrm{Ca}$. $\mathrm{Pb}$ is generally described as presenting a strong affinity for Fe- and Mn-oxides [56]-[58]. As more iron is extracted, more $\mathrm{Pb}$ is released (Figure 6) 

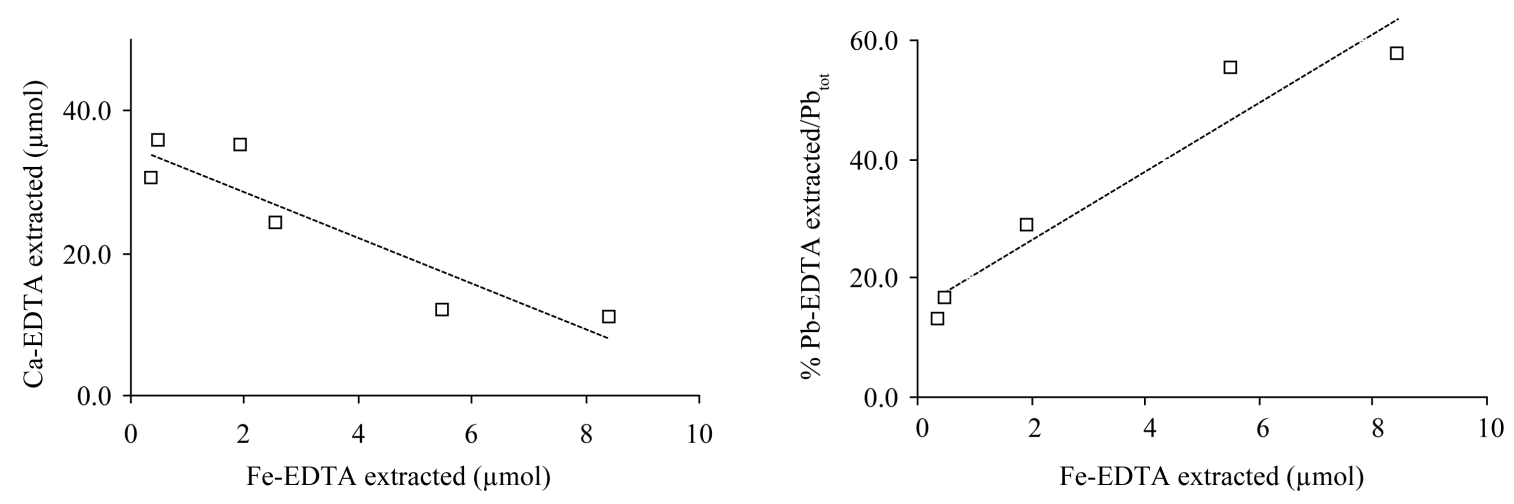

Figure 6. Relationship between Ca-, Fe- and Pb-EDTA extracted in 6 soil samples.

probably due to its adsorption on or occlusion within the iron oxides. Hence, compared with BCR protocol, the lack of extractant (with respect to $\mathrm{Fe}$ ) in the single scheme results in an underestimation of $\mathrm{Pb}$ bound to the reducing fraction. Kim and Song [59] have already reported the co-dissolution effect of $\mathrm{Pb}$ and Fe in soil-EDTA systems and the effect of molar concentration of EDTA on Pb extraction efficiency. Other authors report that the labile pool using high concentration of EDTA $\left(0.05 \mathrm{~mol} \cdot \mathrm{l}^{-1}\right)$ overestimates the metal leachability [45] [54].

The labile pool $\left(\mathrm{F}_{\mathrm{L}}\right)$, estimated by kinetic simulation showed also significant correlation with $\mathrm{F}_{2}(\mathrm{r}=0.48, \mathrm{p}<$ 0.01). As explained above, $\mathrm{F}_{\mathrm{L}}$ like as $\mathrm{F}_{\mathrm{EDTA}}$ involved a portion of $\mathrm{Pb}$ released in the reducing step (bound to Fe-oxides) and varied between soils as a function of $\mathrm{Fe}$ and $\mathrm{Ca}$ total contents as well as the soil pH (Figure 6).

Finally, a principal component analysis was executed to visualize the $\mathrm{Pb}$ and $\mathrm{Cd}$ remobilization, estimated by different extractive schemes, in the three different sites investigated in this work (Figure 7).

The three studied areas are well recognised, on the biplot of the two most meaningful PCs $\left(\mathrm{PC}_{1}\right.$ and $\left.\mathrm{PC}_{2}\right)$, in terms of labile fractions issued from different protocols. This observation indicates the influence of the soil origin on metal behaviours towards different extractive approaches. The different methods of speciation present a general trend in terms of metal mobility i.e. Dong Anh site is characterized by mobile fractions $\left(\mathrm{F}_{1}, \mathrm{~F}_{2}, \mathrm{~F}_{\mathrm{L}}\right.$ and $\mathrm{F}_{\mathrm{EDTA}}$ ) for both $\mathrm{Pb}$ and $\mathrm{Cd}$ while Cau Dien and Thanh Liet sites are characterized by less labile (metal specifically bound) or residual fractions. Thus, the most polluted sample (from Thanh Liet site) presents less availability for $\mathrm{Pb}$ and $\mathrm{Cd}$ and then less potential risks for environment.

\section{Conclusions}

The originality of this manuscript lies in the comparison of three approaches, which are generally used separately in the literature and also in their application in developing countries where little published information is available and much more needed. Another part of the originality of this work is the relative accessibility of the instrumentation required and easy implementation of approaches to assess the metal mobility in a series of urban Vietnamese soils affected by TM contamination.

The measuring of pseudo-total concentrations of $\mathrm{Pb}$ and $\mathrm{Cd}$ proved that, contrary to those obtained by other authors for agricultural soils at other sites irrigated by the same rivers, the sampling points studied in this work are not actually contaminated. However; they could pose a potential risk in the future because of their capacity of transfer, accumulation in the agricultural soils and uptake by vegetables.

The three extractive sequential, single and kinetic schemes used in this work revealed a marked higher availability for $\mathrm{Cd}$ in the investigated zone. Cd was characterized by abundance in the two first steps of BCR protocol, high desorption constant rate and high extractability by EDTA dealing with its association to the exchangeable fraction. $\mathrm{Pb}$ was distinguished of $\mathrm{Cd}$ by its high association to Fe-oxides, lower extractibility by EDTA and lower rate of desorption.

From methodological point of view, the comparison of three approaches has shown their convergence in terms of mobility patterns observed for $\mathrm{Pb}$ and $\mathrm{Cd}$. However, each of them provided some supplementary information. Sequential scheme provided complementary data in terms of metal binding to different soil components. For Pb, the sequential extraction was more aggressive than single extractive approach. This latter did give complementary information on $\mathrm{Pb}$ association with iron-oxides and its lower availability compared with Cd. Single scheme esti- 
$\mathrm{Cd}$

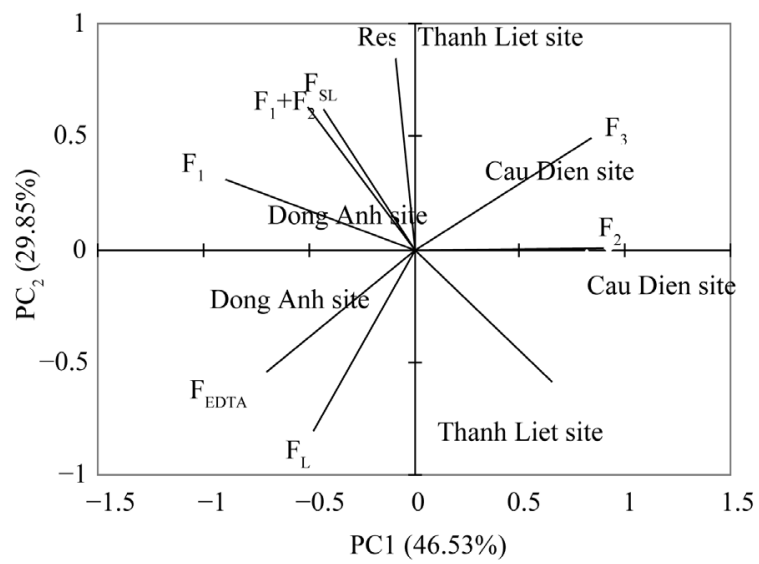

$\mathrm{Pb}$

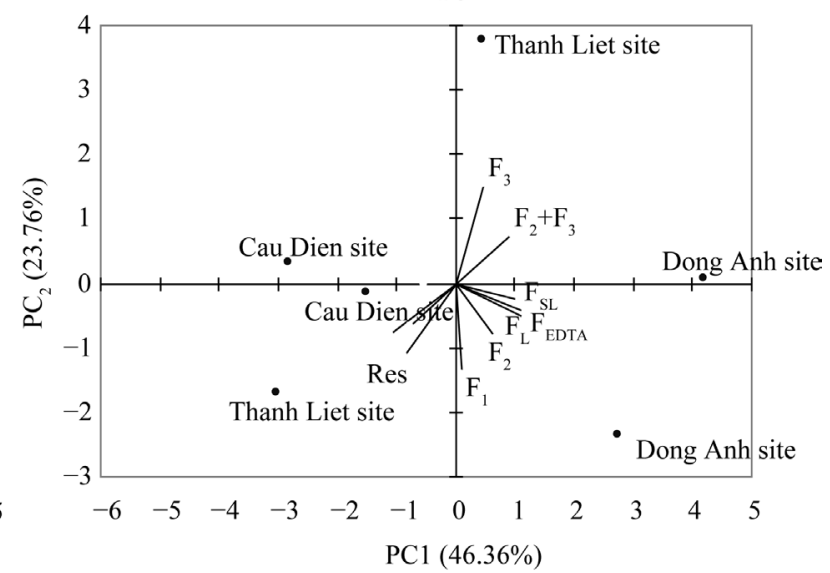

Figure 7. Principal component analysis applied to the fractions obtained from BCR, single and kinetic schemes for $\mathrm{Pb}$ and $\mathrm{Cd}$ in 6 soils (combined plots of scores and loading on $\mathrm{PC}_{1}-\mathrm{PC}_{2}$ ).

mated an overall labile pool in agreement with exchangeable pool for $\mathrm{Cd}$ and reducing pool for $\mathrm{Pb}$. Kinetic approach revealed the presence of two distinct pools in the metal-EDTA fraction and higher rate of desorption for Cd compared to $\mathrm{Pb}$.

For this Vietnamese environmental scenario, EDTA single scheme at equilibrium could be suggested as the best suited and a simple protocol for determination of the mobile pool of $\mathrm{Cd}$ and $\mathrm{Pb}$.

Finally, the results prove, once again, that mobility and lability are operationally defined concepts, soilprotocol- and reagent-dependent. In order to routine estimation of potential availability, it is necessary to consider all factors, related to the operational condition and soil properties, affecting the estimation of remobilized fraction.

\section{Acknowledgements}

The paper was written with support from protocol LOTUS No. 44/2012/HĐ-NĐT, MOST, Vietnam.

\section{References}

[1] MONR. (2010) National Environmental Report Vietnam Environmental Review. Ministry of Natural Resources and Environment, Hanoi, 232.

[2] Huong, N.T.L., Ohtsubo, M. and Higashi, T (2007) Mobility of Heavy Metals in the Sediment of the To Lich River and the Kim Nguu River in Hanoi City. Journal of the Faculty of Agriculture, 52, 179-185.

[3] Ure, A.M. (1991) Trace Element Speciation in Soils, Soil Extracts and Solutions. Microchimica Acta, 104, 49-57. http://dx.doi.org/10.1007/BF01245495

[4] Templeton, D.M., Ariese, F., Cornelis, R., Danielsson, L.G., Muntau, H., Van Leeuwen, H. and Łobinski, R. (2000) Guidelines for Terms Related to Chemical Speciation and Fractionation of Elements: Definitions, Structural Aspects, and Methodological Approaches. Pure and Applied Chemistry, 72, 1453-1470. http://dx.doi.org/10.1351/pac200072081453

[5] Anju, M. and Banerjee, D. (2011) Associations of Cadmium, Zinc, and Lead in Soils from a Lead and Zinc Mining Area as Studied by Single and Sequential Extractions. Environmental Monitoring and Assessment, 176, 67-85. http://dx.doi.org/10.1007/s10661-010-1567-4

[6] Huang, Z.Y., Chen, T., Yu, J. and Qin, D.-P. and Chen, L. (2011) Lead Contamination and Its Potential Sources in Vegetables and Soils of Fujian, China. Environmental Geochemistry and Health, 34, 55-65. http://dx.doi.org/10.1007/s10653-011-9390-6

[7] Little, M.G. and Lee, C.T.A. (2010) Sequential Extraction of Labile Elements and Chemical Characterization of a Basaltic Soil from Mt. Meru, Tanzania. Sequential Extraction of Labile Elements and Chemical Characterization of a Basaltic Soil from Mt. Meru, Tanzania. Journal of African Earth Sciences, 57, 444-454. http://dx.doi.org/10.1016/j.jafrearsci.2009.12.001

[8] Rao, C.R.M., Sahuquillo, A. and Lopez-Sanchez, J.F. (2008) A Review of the Different Methods Applied in Environmental Geochemistry for Single and Sequential Extraction of Trace Elements in Soils and Related Materials. Water, 
Air, \& Soil Pollution, 189, 291-333. http://dx.doi.org/10.1007/s11270-007-9564-0

[9] Rao, C.R.M., Sahuquillo, A. and Lopez-Sanchez, J.F. (2010) Comparison of Single and Sequential Extraction Procedures for the Study of Rare Earth Elements Remobilisation in Different Types of Soils. Analytica Chimica Acta, 662, 128-136. http://dx.doi.org/10.1016/j.aca.2010.01.006

[10] Rauret, G. (1998) Extraction Procedures for the Determination of Heavy Metals in Contaminated Soil and Sediment. Talanta, 46, 449-455. http://dx.doi.org/10.1016/S0039-9140(97)00406-2

[11] Roulier, J.L., Belaud, S. and Coquery, M. (2010) Comparison of Dynamic Mobilization of Co, Cd and Pb in Sediments Using DGT and Metal Mobility Assessed by Sequential Extraction. Chemosphere, 79, 839-843. http://dx.doi.org/10.1016/j.chemosphere.2010.02.056

[12] Zemberyová, M., Barteková, J. and Hagarová, I. (2006) The Utilization of Modified BCR Three-Step Sequential Extraction Procedure for the Fractionation of $\mathrm{Cd}, \mathrm{Cr}, \mathrm{Cu}, \mathrm{Ni}, \mathrm{Pb}$ and $\mathrm{Zn}$ in Soil Reference Materials of Different Origins. Talanta, 70, 973-978. http://dx.doi.org/10.1016/j.talanta.2006.05.057

[13] Zhu, Q.H., Huang, D.Y., Liu, S.L., Luo, Z.C., Zhu, H.H., Zhou, B., Lei, M., Rao, X.M. and Cao, X.L. (2012) Assessment of Single Extraction Methods for Evaluating the Immobilization Effect of Amendments on Cadmium in Contaminated Acidic Paddy Soil. Plant Soil and Environment, 58, 98-103.

[14] Quevauviller, P., Rauret, G. and Griepink, B. (1993) Single and Sequential Extraction in Sediments and Soils. International Journal of Environmental Analytical Chemistry, 51, 231-235. http://dx.doi.org/10.1080/03067319308027629

[15] Mossop, K.F. and Davidson, C.M. (2003) Comparison of Original and Modified BCR Sequential Extraction Procedures for the Fractionation of Copper, Iron, Lead, Manganese and Zinc in Soils and Sediments. Analytica Chimica Acta, 478, 111-118. http://dx.doi.org/10.1016/S0003-2670(02)01485-X

[16] Rauret, G., Lopez-Sanchez, J.F., Sahuquillo, A., Rubio, R., Davidson, C., Ure, A.M. and Quevauviller, P. (1999) Improvement of the BCR Three Step Sequential Extraction Procedure Prior to the Certification of New Sediment and Soil Reference Materials. Journal of Environmental Monitoring, 1, 57-61. http://dx.doi.org/10.1039/a807854h

[17] Ure, A.M., Quevauviller P., Muntau, H. and Griepink, B. (1993) Speciation of Heavy Metals in Soils and Sediments. An Account of the Improvement and Harmonization of Extraction Techniques Undertaken under the Auspices of the BCR of the Commission of the European Communities. International Journal of Environmental Analytical Chemistry, 51, 135-151. http://dx.doi.org/10.1080/03067319308027619

[18] Manouchehri, N. and Bermond, A. (2006) Study of Trace Metal Partitioning between Soil-EDTA Extracts and Chelex100 Resin. Analytica Chemica Acta, 557, 337-343.

[19] Singh, S.P., Tack, F.M.G. and Verloo, M.G. (1996) Solid-Phase Distribution of Heavy Metals as Affected by Single Reagent Extraction in Dredged Sediment Derived Surface Soils. Chemical Speciation and Bioavailability, 8, 105-110.

[20] Alvarez, J.M., Lopez-Valdivia, L.M., Novillo, J., Obrador, A. and Rico, M.I. (2006) Comparison of EDTA and Sequential Extraction Tests for Phytoavailability Prediction of Manganeses and Zinc in Agricultural Alkaline Soils. Geoderma, 132, 450-463. http://dx.doi.org/10.1016/j.geoderma.2005.06.009

[21] Manouchehri, N. and Bermond, A. (2009) EDTA in Soil Science: A Review of Its Application in Soil Trace Metal Investigations. Terrestrial and Aquatic Environmental Technology, 3, 1-15.

[22] Ghestem, J.P. (1997) Extraction par l'edta de metaux traces de sols pollues; application a l'etude de la faisabilite d'une speciation de ces metaux. PhD Thesis, Thèse Université de Paris 7 Denis Diderot, Paris.

[23] Bermond, A., Ghestem, J.P. and Yousfi, I. (1998) Kinetic Approach to the Chemical Speciation of Trace Metals in Soils. Analyst, 123, 785-790. http://dx.doi.org/10.1039/a707776i

[24] Fangueiro, D., Bermond, A., Santos, E., Carapuça, H. and Duarte, A. (2002) Heavy Metal Mobility Assessment in Sediments Based on a Kinetic Approach of the EDTA Extraction: Search for Optimal Experimental Conditions. Analytica Chimica Acta, 459, 245-256. http://dx.doi.org/10.1016/S0003-2670(02)00134-4

[25] Wasay, S.A., Barrington, S.F., Tokunagal, S. and Prasher, S. (2007) Kinetics of Heavy Metal Desorption from Three Soils Using Citric Acid, Tartaric Acid, and EDTA. Journal of Environmental Engineering and Science, 6, 611-622.

[26] Manouchehri, N., Besançon, S. and Bermond, A. (2011) Kinetic Characterizing of Soil Trace Metal Availability Using Soil/EDTA/Chelex Mixture. Chemosphere, 83, 997-1004. http://dx.doi.org/10.1016/j.chemosphere.2011.02.010

[27] Iqbal, M., Lamy, I. and Bermond, A. (2013) Impact of Miscanthus Cultivation on Trace Metal Availability in Contaminated Agricultural Soils: Complementary Insights from Kinetic Extraction and Physical Fractionation. Chemosphere, 91, 287-294. http://dx.doi.org/10.1016/j.chemosphere.2012.11.032

[28] Harper, M.P., Davison, W., Zhang, H. and Tych, W. (1998) Kinetics of Metal Exchange between Solids and Solutions in Sediments and Soils Interpreted from DGT Measured Fluxes. Geochimicaet Cosmochimica Acta, 62, 2757-2770. http://dx.doi.org/10.1016/S0016-7037(98)00186-0

[29] Ernstberger, H., Zhang, H., Tye, A.M., Young, S. and Davison, W. (2005) Desorption Kinetics of Cd, Zn and Ni Mea- 
sured in Soils by DGT. Environmental Science and Technology, 39, 1591-1597. http://dx.doi.org/10.1021/es048534d

[30] Manouchehri, N., Besançon, S. and Bermond, A. (2006) Major and Trace Metal Extraction from Soil by EDTA: Equilibrium and Kinetic Studies. Analytica Chimica Acta, 559, 105-112. http://dx.doi.org/10.1016/j.aca.2005.11.050

[31] Huong, N.T.L., Ohtsubo, M., Li, L., Higashi, T. and Kanayama, M. (2010) Heavy-Metal Contamination of Soil and Vegetables in Wastewater Irrigated Agricultural Soil in a Suburban Area of Hanoi, Vietnam. Communications in Soil Science and Plant Analysis, 41, 390-407. http://dx.doi.org/10.1080/00103620903494350

[32] Huong, N.T.L., Ohtsubo, M., Higashi, T. and Kanayama, M. (2012) Heavy Metal Concentration in Sediments of the Nhue River and Its Water-Irrigated Farmland Soil in the Suburbs of Hanoi, Vietnam. Soil and Sediment Contamination: An International Journal, 21, 364-381. http://dx.doi.org/10.1080/15320383.2012.649379

[33] Vietnam Standard (2002) Soil Quality-Maximum Allowable Limits of Heavy Metals in the Soil.

[34] Mench, M., Baize, D. and Mocquot, B. (1997) Cadmium Availability to Wheat in Five Soil Series from the Yonne District, Burgundy, France. Environmental Pollution, 95, 93-103. http://dx.doi.org/10.1016/S0269-7491(96)00078-4

[35] Kuo, S., Heilman, P.E. and Baker, A.S. (1993) Distribution and Forms of Copper, Zinc, Cadmium, Iron, and Manganese in Soils Near a Copper Smelter1. Soil Science, 135, 101-109. http://dx.doi.org/10.1097/00010694-198302000-00004

[36] Knight, B.P., Chaudri, A.M., McGrath, S.P. and Giller, K.E. (1998) Determination of Chemical Availability of Cadmium and Zinc in Soils Using Inert Soil Moisture Samplers. Environmental Pollution, 99, 293-298. http://dx.doi.org/10.1016/S0269-7491(98)00021-9

[37] Moreno-Jiménez, E., Penãlosa, J.M., Manzano, R., Carpena-Ruiz, R.O., Gamarra, R. and Esteban, E. (2009) Heavy Metals Distribution in Soils Surrounding an Abandoned Mine in NW Madrid (Spain) and Their Transference to Wild Flora. Journal of Hazardous Materials, 162, 854-859. http://dx.doi.org/10.1016/j.jhazmat.2008.05.109

[38] Stone, M. and Marsalek, J. (1996) Trace Metal Composition and Speciation in Street Sediment: Sault Ste. Marie, Canada. Water Air and Soil Pollution, 87, 149-169. http://dx.doi.org/10.1007/BF00696834

[39] Deuel, L.E. and Holliday, G.H. (1998) Geochemical Partitioning of Metals in Spent Drilling Fluid Solids. Journal of Energy Resources Technology, 120, 208-214. http://dx.doi.org/10.1115/1.2795037

[40] Farkas, A., Erratico, C. and Viagna, L. (2007) Assessment of the Environmental Significance of Heavy Metal Pollution in Surficial Sediments of the River Po. Chemosphere, 68, 761-768. http://dx.doi.org/10.1016/j.chemosphere.2006.12.099

[41] Tejowulan, R.S. and Hendershot, W.H. (1998) Removal of Trace Metals from Contaminated Soils Using EDTA Incorporating Resin Trapping Techniques. Environmental Pollution, 103, 135-142. http://dx.doi.org/10.1016/S0269-7491(98)00080-3

[42] Varrault, G. (2001) Etude cinétique de l’extraction des métaux traces des sols; application à l’évaluation de l'efficacité de techniques de réhabilitation in situ. Thèse Université Paris 7, Paris.

[43] McGrath, D. (1996) Application of Single and Sequential Extraction Procedures to Polluted and Unpolluted Soils. Science of the Total Environment, 178, 37-44. http://dx.doi.org/10.1016/0048-9697(95)04795-6

[44] Banat, K.M., Howari, F.M. and Tomah, M.M. (2007) Chemical Fractionation and Heavy Metal Distribution in Agricultural Soils, North of Jordan Valley. Soil and Sediment Contamination, 16, 89-107.

[45] Labanowski, J., Monna, F., Bermond, A., Cambier, P., Fernandez, C., Lamy, I. and van Oort, F. (2008) Kinetic Extractions to Assess Mobilization of $\mathrm{Zn}, \mathrm{Pb}, \mathrm{Cu}$, and $\mathrm{Cd}$ in a Metal Contaminated Soil: EDTA vs. Citrate. Environmental Pollution, 152, 693-701. http://dx.doi.org/10.1016/j.envpol.2007.06.054

[46] Gandois, L., Probst, A. and Dumat, C. (2010) Modelling Trace Metal Extractability and Solubility in French Forest Soils by Using Soil Properties. European Journal of Soil Science, 61, 271-286. http://dx.doi.org/10.1111/j.1365-2389.2009.01215.x

[47] Chrastný, V., Komárek, M., Jrovcová, E. and Stíchová, J. (2008) A Critical Evaluation of the 0.05 M EDTA Extraction of $\mathrm{Pb}$ from Forest Soils. International Journal of Environmental Analytical Chemistry, 88, 385-396. http://dx.doi.org/10.1080/03067310701744283

[48] Korf, E.P., Consoli, N.C., Tímbola, R.S. and Santos, G.C. (2011) Metal Transport Parameters in Residual Soil with an Undisturbed and Remolded Structure Percolated by an Acid Solution. Journal of Environment Protection, 2, 10761083. http://dx.doi.org/10.4236/jep.2011.28124

[49] Makovníková, J. and Barančíková, G. (2009) Assessment of Transport Risk of Cadmium and Lead on the Basis of Immobilisation Capability of Soil. Soil and Water Research, 1, 10-16.

[50] Papassiopi, N., Skoufadis, C., Tambouris, S. and Kontopoulos, A. (1998) Integrated Leaching Processes for the Removal of Heavy Metals from Heavily Contaminated Soils. Thomas Telford, London, 461-470. 
[51] Theodoratos, P., Papassiopi, N., Georgoudis, T. and Kontopoulos, A. (2000) Selective Removal of Lead from Calcareous Polluted Soils Using the Ca-EDTA Salt. Water Air and Soil Pollution, 122, 351-368. http://dx.doi.org/10.1023/A:1005295119231

[52] Chakraborty, P. (2012) Speciation of Co, Ni and Cu in the Coastal and Estuarine Sediments: Some Fundamental Characteristics. Journal of Geochemical Exploration. 115, 13-23. http://dx.doi.org/10.1016/j.gexplo.2012.01.008

[53] Mallmanna, F.J.K., Santosa, D.R., Cambier, P., Labanowski, J., Lamy, I., Santannad, M.A., Tessier, D. and van Oort, F. (2012) Using a Two Site-Reactive Model for Simulating One Century Changes of Zn and Pb Concentration Profiles in Soils Affected by Metallurgical Fallout. Environmental Pollution, 162, 294-302. http://dx.doi.org/10.1016/j.envpol.2011.11.039

[54] Santos, S., Costa, C.A.E., Duarte, A.C., Scherer, H.W., Schneider, R.J., Esteves, V.I. and Santos, E.B.H. (2010) Influence of Different Organic Amendments on the Potential Availability of Metals from Soil: A Study on Metal Fractionation and Extraction Kinetics by EDTA. Chemosphere, 78. 389-396. http://dx.doi.org/10.1016/j.chemosphere.2009.11.008

[55] Bermond, A., Varrault, G., Sappin-Didier, V. and Mench, M. (2005) A Kinetic Approach to Predict Soil Trace Metal Bioavailability: Preliminary Results. Plant and Soil, 275, 21-29. http://dx.doi.org/10.1007/s11104-004-7599-1

[56] Barona, A. and Romero, F. (1996) Fractionation of Lead in Soils and Its Influence on the Extractive Cleaning with EDTA. Environmental Technology, 17, 63-70. http://dx.doi.org/10.1080/09593331708616361

[57] Herbert, R.B. (1997) Partitioning of Heavy Metals in Podzol Soils Contaminated by Mine Drainage Waters, Dalarna, Sweden. Water Air and Soil Pollution, 96, 39-59. http://dx.doi.org/10.1007/BF02407195

[58] Raksasataya, M., Langdon, A.G. and Kim, N.D. (1996) Assessment of the Extent of Lead Redistribution during Sequential Extraction by Two Different Methods. Analytica Chimica Acta, 332, 1-14. http://dx.doi.org/10.1016/0003-2670(96)00227-9

[59] Kim, C., Lee, Y. and Ong, S.K. (2003) Factors Affecting EDTA Extraction of Lead from Lead-Contaminated Soils. Chemosphere, 51, 845-853. http://dx.doi.org/10.1016/S0045-6535(03)00155-3 
Scientific Research Publishing (SCIRP) is one of the largest Open Access journal publishers. It is currently publishing more than 200 open access, online, peer-reviewed journals covering a wide range of academic disciplines. SCIRP serves the worldwide academic communities and contributes to the progress and application of science with its publication.

Other selected journals from SCIRP are listed as below. Submit your manuscript to us via either submit@scirp.org or Online Submission Portal.
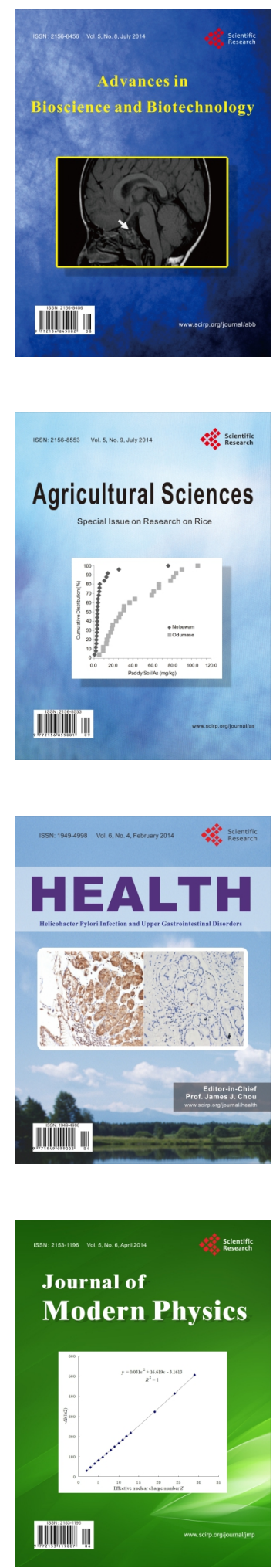
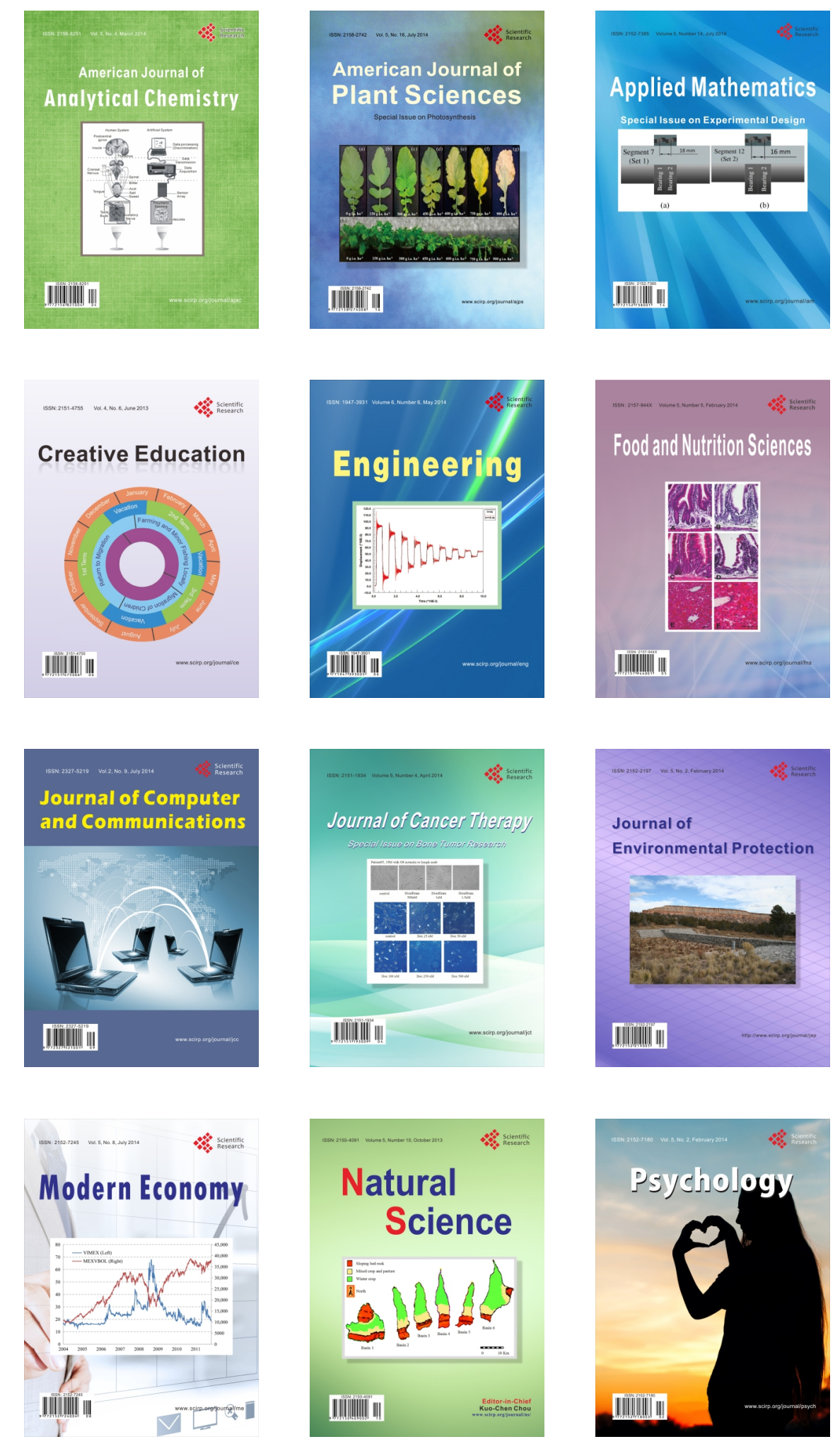